\title{
APPLICATION OF A GENETIC ALGORITHM FOR THE OPTIMIZATION OF ENRICHMENT ZONING AND GADOLINIA FUEL $\left(\mathrm{UO}_{2} / \mathrm{Gd}_{2} \mathrm{O}_{3}\right)$ ROD DESIGNS IN OPR1000s
}

\author{
TAE JE KWON ${ }^{1,2, *}$ and JONG KYUNG KIM ${ }^{1}$ \\ ${ }^{1}$ Department of Nuclear Engineering, Hanyang University \\ Seoul 133-791, Korea \\ ${ }^{2}$ KEPCO Nuclear Fuel \\ 989 Daeduk-daero, Yuseong, Daejeon 305-353, Korea \\ "Corresponding author. E-mail : tjkwon@knfc.co.kr
}

Received August 23, 2011

Accepted for Publication February 01, 2012

\begin{abstract}
A new effective methodology for optimizing the enrichment of low-enriched zones as well as gadolinia fuel $\left(\mathrm{UO}_{2} / \mathrm{Gd}_{2} \mathrm{O}_{3}\right)$ rod designs in PLUS7 fuel assemblies was developed to minimize the maximum peak power in the core and to maximize the cycle lifetime. An automated link code was developed to integrate the genetic algorithm (GA) and the core design code package of ALPHA/PHOENIX-P/ANC and to generate and evaluate the candidates to be optimized efficiently through the integrated code package. This study introduces an optimization technique for the optimization of gadolinia fuel rod designs in order to effectively reduce the peak powers for a few hot assemblies simultaneously during the cycle. Coupled with the gadolinia optimization, the optimum enrichments were determined using the same automated code package. Applying this technique to the reference core of Ulchin Unit 4 Cycle 11, the gadolinia fuel rods in each hot assembly were optimized to different numbers and positions from their original designs, and the maximum peak power was decreased by $2.5 \%$, while the independent optimization technique showed a decrease of $1.6 \%$ for the same fuel assembly. The lower enrichments at the fuel rods adjacent to the corner gap (CG), guide tube (GT), and instrumentation tube (IT) were optimized from the current 4.1, 4.1, 4.1 w/o to 4.65, $4.2,4.2 \mathrm{w} / \mathrm{o}$. The increase in the cycle lifetime achieved through this methodology was 5 effective full-power days (EFPD) on an ideal equilibrium cycle basis while keeping the peak power as low as $2.3 \%$ compared with the original design.
\end{abstract}

KEYWORDS : Enrichment Zoning, Gadolinia, Genetic Algorithm, Optimization, PLUS7, Power Peaking

\section{INTRODUCTION}

The burnable absorber (BA) rods in pressurized water reactors (PWR) are essential for controlling power distribution and thus maintaining the power peaking factors of the fuel assembly within limits, as well as to ensure that the moderator temperature coefficients (MTC) are consistent with their limits. In addition to the use of BA rods, the enrichment zoning is important for controlling peak power because of the designed configuration of the PLUS7 [1] fuel assembly (FA) loaded in Optimized Power Reactor 1000 (OPR1000) cores. As shown in Fig. 1, the area of the guide tube (GT) and the instrumentation tube (IT) filled with water is equivalent to that of four fuel rods, which makes many more thermal neutrons than the other areas, and thus results in an increase in the power of the fuel rods adjacent to the GT and IT. Also, the relatively wide gap between fuel assemblies increases the power in the fuel rods around the corner gap (CG). In order to control the power peaking factor in the reload core designs, each fuel assembly contains zones of lower enrichment fuel pins adjacent to the regions [2]. If the zoning technique is not applied in reload core designs, the maximum peak

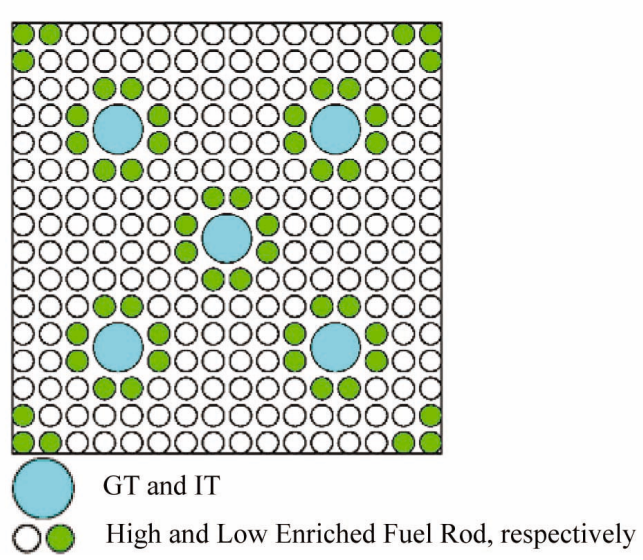

Fig. 1. Cross-Section View of PLUS7 Fuel Assembly 
power increases up to approximately $6 \%$, which results in a decrease in the corresponding operating margin. Therefore, the use of the zoning technique is inevitable, and this is a unique feature for the fuel assembly loaded in OPR1000 cores.

The currently used gadolinia fuel $\left(\mathrm{UO}_{2} / \mathrm{Gd}_{2} \mathrm{O}_{3}\right)$ rod (or $\mathrm{BA}$ ) designs in assemblies and the lower enrichment within a fuel assembly are determined by unit assembly calculations assuming infinite boundary conditions with the trial and error method based on the engineers' experience [3]. However, the optimized BA patterns from the infinite lattice calculations do not work well in loading pattern designs because the boundary conditions in 3D cores differ from the infinite boundary conditions. Furthermore, with the peaking factor increases due to the adoption of longer cycle operations and lower leakage loading pattern designs, the need to secure safety margin has led to the application of optimization techniques to the gadolinia fuel rod designs and the enrichment zoning in order to lower the maximum peak power in the cores.

This study uses a genetic algorithm (GA) to optimize the lower enrichment within an assembly coupled with optimizing the gadolinia fuel rod designs for the PLUS7 fuel assembly. The GA can be applied to optimize a problem by evolving the population into the next generation of solutions with three genetic operators: selection, crossover, and mutation. The GA driver [4] and the core design code package ALPHA/PHOENIX-P/ANC [5, 6], were integrated by the automated link code developed in this study to minimize the power peaking in the core over the cycle and to maximize the cycle lifetime. The new GAALPHA/PHOENIX-P/ANC code package was efficiently used in these optimization calculations.

Almost all reload cores include two hot assemblies, or three in rare cases, during the cycle. Therefore, the optimization of BA designs for at least two hot assemblies is effective for controlling the radial peak power in a core during the cycle. The typical approach in the optimization process is to deal with each hot assembly independently to optimize the BA designs, and then insert these different BA designs into each hot assembly in order to perform the depletion calculations. In contrast, the simultaneous optimization technique developed in this study is more effective and efficient than the previous technique because the new technique can optimize all gadolinia-bearing fresh fuels simultaneously, but it is not necessary since doing so consumes too much computing time relative to its effectiveness. It is sufficient to treat a few hot assemblies in loading pattern designs as described above.

Coupled with the simultaneous optimization of gadolinia fuel rods, the main task of this study was to apply the GA method to determine the optimum lower enrichment in the PLUS7 fuel assembly. Moreover, because the peak powers and the cycle lifetime are influenced by the BA designs as well as the enrichments, it is highly effective to optimize the enrichment coupled with the optimum BA designs. It is also important to follow the order described below when performing the optimizations. Even though the optimized enrichment of each zone impacts the peak power in the core, the influence is relatively small compared with that of the optimized gadolinia designs. We also found that the reduction in the peak power resulting from the enrichment optimization was less effective than expected when the optimum BA designs were not applied. Therefore, in order to ensure that the optimization confers significant effects, the BA design should be optimized first, followed by the zoning optimization.

Similar studies applying the GA method to optimize gadolinia BA designs have been conducted. Yilmaz, Ivanov, and Levine developed a GA method with the CASMO-4/SIMULATE-3 code package to optimize the gadolinia fuel rod configuration, and the code was used to vary the placement and number of gadolinia fuel rods in only fresh fuel assemblies with the highest radial power distribution [7]. This study introduces the $\mathrm{K}_{\mathrm{inf}}$ filter to save computing time, but this procedure was performed only for the assembly with the highest radial power distribution.

Yilmaz, Ivanov, and Levine also used the same GA algorithm to place BAs into all of the fresh fuel positions. The applied BA configurations were optimized in advance [8]. Even though pre-optimized BA configurations are used, if their placement is optimized based on the infinite boundary condition, then a large number of shuffling and rotations of burnt fuels are required when optimizing a loading pattern with a 3D core model. Therefore, 3D calculations are required for the BA optimizations, but the optimized patterns based on 3D core models are not always effective when applied to other locations or to other loading patterns because their boundary conditions differ from those of the previous optimization. Therefore, the effectiveness may not be as good as expected when placing the pre-optimized BAs, even though the optimized patterns are based on $3 \mathrm{D}$ calculations.

\section{REFERENCE CORE AND FUEL ASSEMBLY}

The reference core considered in this study was the Ulchin Nuclear Power Plant Unit 4 core, which is composed of 177 PLUS7 fuel assemblies with a 16x16 array of 236 fuel rods, 4 GT and 1 IT, as shown in Fig. 1. The reference core loading pattern of Cycle 11 is shown in Fig. 2. Each assembly indicates the fuel assembly information, such as the region number and the number of gadolinia fuel rods used. A total of 12 fresh fuel assemblies are in the reference octant core symmetry, which is the same as a total of 69 fresh fuels in the full core. There were two hot assemblies during the cycle. The fuel assembly at $(3,5)$ showed peak power at BOC (beginning of cycle), and the second peak occurred at the 


\begin{tabular}{|c|c|c|c|c|c|c|c|c|}
\hline & 1 & 2 & 3 & 4 & 5 & 6 & 7 & 8 \\
\hline 1 & $\begin{array}{c}\mathrm{O} \\
\text { FEED } \\
2.0\end{array}$ & $\begin{array}{c}\mathrm{N} \\
1 \mathrm{X} \\
4.5 / 4.0 \\
12 / 6.0\end{array}$ & $\begin{array}{c}\mathrm{M} \\
2 \mathrm{X} \\
4.5 / 4.0 \\
12 / 6.0\end{array}$ & $\begin{array}{c}\mathrm{N} \\
1 \mathrm{X} \\
4.5 / 4.0\end{array}$ & $\begin{array}{c}\mathrm{M} \\
2 \mathrm{X} \\
4.5 / 4.0\end{array}$ & $\begin{array}{c}\mathrm{O} \\
\text { FEED } \\
4.65 / 4.1 \\
16 / 8.0\end{array}$ & $\begin{array}{c}\mathrm{N} \\
1 \mathrm{X} \\
4.5 / 4.0 \\
12 / 6.0\end{array}$ & $\begin{array}{c}\mathrm{O} \\
\mathrm{FEED} \\
4.65 / 4.1\end{array}$ \\
\hline 2 & & $\begin{array}{c}\mathrm{N} \\
1 \mathrm{X} \\
4.5 / 4.0 \\
8 / 6.0\end{array}$ & $\begin{array}{c}\mathrm{N} \\
1 \mathrm{X} \\
4.5 / 4.0 \\
8 / 6.0\end{array}$ & $\begin{array}{c}\text { O } \\
\text { FEED } \\
4.65 / 4.1 \\
20 / 8.0 \\
1.303 / 1.483 \\
\end{array}$ & $\begin{array}{c}\mathrm{N} \\
1 \mathrm{X} \\
4.5 / 4.0 \\
12 / 8.0\end{array}$ & $\begin{array}{c}\mathrm{N} \\
1 \mathrm{X} \\
4.5 / 4.0 \\
12 / 8.0\end{array}$ & $\begin{array}{c}\text { O } \\
\text { FEED } \\
4.65 / 4.1 \\
12 / 8.0\end{array}$ & $\begin{array}{c}\mathrm{N} \\
1 \mathrm{X} \\
4.5 / 4.0\end{array}$ \\
\hline 3 & & & $\begin{array}{c}\mathrm{O} \\
\text { FEED } \\
4.65 / 4.1 \\
16 / 8.0\end{array}$ & $\begin{array}{c}\mathrm{M} \\
2 \mathrm{X} \\
4.5 / 4.0\end{array}$ & $\begin{array}{c}\mathrm{O} \\
\text { FEED } \\
4.65 / 4.1 \\
12 / 8.0 \\
1.506 / 1.470\end{array}$ & $\begin{array}{c}\mathrm{N} \\
1 \mathrm{X} \\
4.5 / 4.0 \\
12 / 6.0\end{array}$ & $\begin{array}{c}\mathrm{O} \\
\text { FEED } \\
4.65 / 4.1 \\
12 / 8.0\end{array}$ & $\begin{array}{c}\mathrm{M} \\
2 \mathrm{X} \\
4.5 / 4.0 \\
8 / 6.0\end{array}$ \\
\hline 4 & & & & $\begin{array}{c}\mathrm{O} \\
\text { FEED } \\
4.65 / 4.1 \\
16 / 8.0\end{array}$ & $\begin{array}{c}\mathrm{M} \\
2 \mathrm{X} \\
4.5 / 4.0 \\
12 / 6.0\end{array}$ & $\begin{array}{c}\mathrm{N} \\
1 \mathrm{X} \\
4.5 / 4.0 \\
8 / 6.0\end{array}$ & $\begin{array}{c}\mathrm{O} \\
\text { FEED } \\
4.65 / 4.1\end{array}$ & \\
\hline 5 & & & & & $\begin{array}{c}\mathrm{O} \\
\text { FEED } \\
4.65 / 4.1 \\
12 / 8.0\end{array}$ & $\begin{array}{c}\mathrm{O} \\
\text { FEED } \\
4.65 / 4.1 \\
8 / 8.0\end{array}$ & $\begin{array}{c}\mathrm{M} \\
2 \mathrm{X} \\
4.5 / 4.0 \\
8 / 6.0\end{array}$ & \\
\hline 6 & $\begin{array}{l}\text { Region } \\
\text { Fuel Type } \\
\text { Enrichme } \\
\text { Number } \\
\text { Peak pow }\end{array}$ & $\begin{array}{l}\text { D: Fresh } \\
\text { ligh/Low } \\
\text { olinia roc } \\
30 L / 12 \mathrm{C}\end{array}$ & $\begin{array}{l}\text { once burn } \\
\mathrm{O}_{3} \\
\text { MTU }\end{array}$ & $\mathrm{x}$ : twice bur & & $\begin{array}{c}\mathrm{M} \\
2 \mathrm{X} \\
4.5 / 4.0 \\
12 / 6.0\end{array}$ & & \\
\hline
\end{tabular}

Fig. 2. Reference Octant Core Loading Pattern for Ulchin Unit 4, Cycle 11

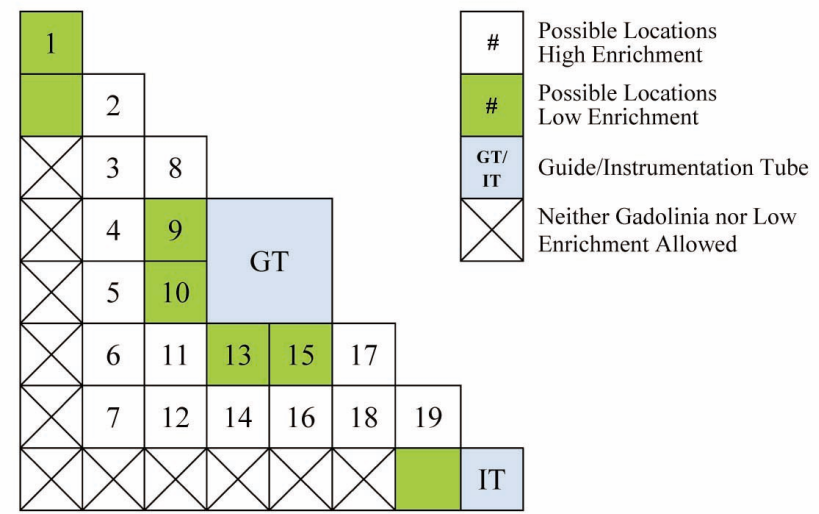

Fig. 3. PLUS7 Octant Model for BA Optimization

assembly located at $(2,4)$ when the $\mathrm{Gd}_{2} \mathrm{O}_{3}$ burned out (around 12 GWD/MTU).

Figures 3 and 4 show that the octant symmetries of the PLUS7 fuel assembly, which has 1 GT and 1 IT. The gadolinia fuel rods can be placed in any of the 19 different positions numbered in Fig. 3. Each fuel rod must be multiplied by 4 or 8 to obtain the total number of fuel rods in the full fuel assembly. To lower the peak power in

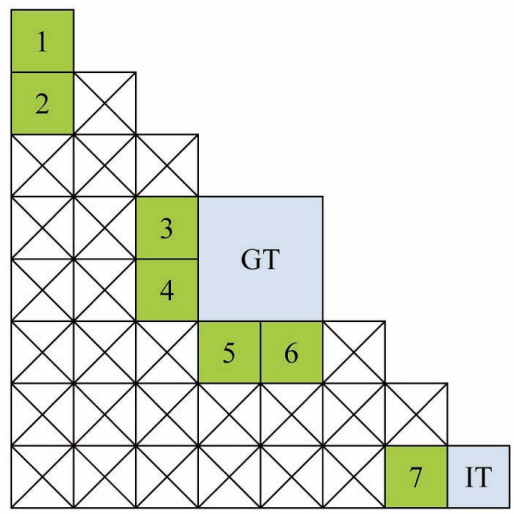

Fig. 4. PLUS7 Octant Model for Enrichment Optimization

those fuel rods, the enrichments currently used in the lower zones are 4.1, 4.1, and $4.1 \mathrm{w} / \mathrm{o}$ in the fuel rods adjacent to CG, GT, and IT, respectively, while the enrichment in the higher zone is $4.65 \mathrm{w} / \mathrm{o}$.

The enrichment of $\mathrm{U}^{235}$ currently used in a gadolinia fuel rod is $2.0 \mathrm{w} / \mathrm{o}$ and increases to $2.2 \mathrm{w} / \mathrm{o}$ in the subsequent cycle. The much lower enrichment of gadolinia fuel rods is due to degraded thermal conductivity and low melting point of the $\mathrm{UO}_{2} / \mathrm{Gd}_{2} \mathrm{O}_{3}$ mixture, which are crucial 
disadvantages. The $\mathrm{Gd}_{2} \mathrm{O}_{3}$ concentrations of $4.0 \mathrm{w} / \mathrm{o}, 6.0$ w/o, or $8.0 \mathrm{w} / \mathrm{o}$ are used in each fuel assembly, but the only single gadolinium concentration is used within an assembly in order to avoid complexity in the fuel fabrication process. There are $8,12,16$, and $20 \mathrm{UO}_{2} / \mathrm{Gd}_{2} \mathrm{O}_{3}$ rods per assembly, respectively, used in the loading pattern (Fig. 2).

There are only seven different positions where the low enriched fuel rods can be located, while the gadolinia BA design allows 19, as shown in Figs. 3 and 4. The optimization of gadolinia fuel rods was performed simultaneously for two hot assemblies located at $(2,4)$ and $(3,5)$, respectively. After applying the optimized BA designs, the optimum lower enrichment was also determined from these two hot assemblies.

\section{METHODOLOGY}

\subsection{Genetic Algorithm}

The GA is a stochastic optimization method based on the mechanics of natural selection and natural genetics $[9,10]$. GAs use the population of points instead of a single point, are relatively insensitive to the problem being optimized, and are theoretically and empirically proven to provide robust search in complex spaces [9]. After an initial population of a trial solution is generated randomly, the GA first decodes the genetic forms (genotypes) into their parameter set (phenotypes) so they can be evaluated by core design codes for their fitness values, which are the objective functions. In this paper the parameter sets are the gadolinia BA designs or the enrichment configuration to be optimized, and the objectives are to minimize the power peaking over the cycle and maximize the cycle energy, which means maximizing the critical boron concentration at the end of cycle (EOC). Populations with higher fitness values have a higher probability of contributing one or more offspring in the next generation.

The phenotypes are then encoded into their corresponding genotypes. As shown in Section 3.2, the genotype is the bit-string representation of the phenotype. The selection operator of the GA then chooses which solutions in the current population will contribute to the next generation of solutions. Phenotypes with higher fitness values have a better chance of surviving and contributing to the next generation through crossover and mutation. The GA processes the genotypes to create new genotypes representing a different parameter set by using crossover and mutation operators. The crossover operator recombines traits from two parents to form two offspring that are better than either of the parents, i.e., with improved fitness as described above. The remaining offspring should then receive the worst traits from each parent, and will probably not survive another generation. The mutation operator makes small random changes to the solutions. If the mutation probability is too low, the fitness no longer increases and it approaches a local solution. Conversely, if the probability is too high, the GA becomes a random search problem [10]. The process repeats until the required generation number is reached and/or meeting the allowable error of fitness values between generations. The process is described in Section 3.3.

A GA driver [4] programmed for public use has been modified in this study to optimize the enrichment zoning and the BA designs for PLUS7 fuel assemblies. The genetic operators such as tournament selection, single-point crossover, and creep and jump mutation were used in this study, and the applied probabilities of crossover, creep and jump mutation were $0.5,0.02$ and 0.01 , respectively, which were heuristically determined. The population size of 10 was chosen so that it would not exceed the limited size of cross-section sets of 3D ANC code [5, 6], and yielded satisfactory results.

\subsection{Phenotype and Genotype Structures}

Genotype describes the genetic constitution of an organism, while phenotype is the expression of that genotype in a particular organism. The genotype structure uses a bit string representation that encodes the different parameter set, e.g., the gadolinia BA designs and the enrichment configuration in this study. A bit-string is simply a one-dimensional array of bits, and each bit has a value of 0 or 1 . In the case of gadolinia BA optimization, since there are 19 different fuel pin positions in which a gadolinia fuel rod can be placed in the octant fuel assembly model shown in Fig. 3, 5 bits (i.e., $2^{4}=16 \leq 19 \leq 32=2^{5}$ ) are the minimum necessary to represent all the positions. Also, three gadolinia fuel rods can be placed in the octant fuel assembly model to simulate 20 and 12 gadolinia fuel rods at the fuel assembly locations $(2,4)$ and $(3,5)$, respectively. The maximum number of gadolinia fuel rods in each full fuel assembly is $24(3 \times 8)$. For this reason, three parameters were defined in the GA calculations, each representing one of the gadolinia fuel rod positions in the model. Each population therefore consists of 15 bits ( 5 bits/parameter $\mathrm{x} 3$ parameters). The optimum gadolinia BA designs were determined by performing repeated GA runs with different parameters.

Encoding gadolinia fuel rod positions (i.e., converting a phenotype into a genotype) is straightforward. For each position in a fuel assembly, the phenotype number places the gadolinia fuel rod according to the numbering scheme shown in Fig. 3. The decision variables corresponding to the phenotype number (i.e., gadolinia fuel rod positions in an assembly) are shown in Fig. 5 with their corresponding binary numbers used in the genotype.

In the case of optimizing the lower enrichment, there are seven different fuel rod positions in which any different enrichment can be placed as shown in Fig. 4. Because any type of enrichment can be placed at each of seven positions, seven parameters should be defined in this problem. Through this approach a maximum of seven 


\begin{tabular}{|c|c|c|c|c|c|}
\hline \multirow{2}{*}{ Number } & \multirow{2}{*}{ 5-Bit ${ }^{*}$ Binary Bits } & \multicolumn{2}{|c|}{ BA Optimization } & \multicolumn{2}{|c|}{ Enrichment Zoning } \\
\hline & & $\begin{array}{l}\text { Decision Variable } \\
\text { Position Number }\end{array}$ & $\begin{array}{l}\text { Corresponding } \\
\text { Position }\end{array}$ & $\begin{array}{l}\text { Enrichment } \\
\text { Number }\end{array}$ & $\begin{array}{l}\text { Corresponding } \\
\text { Enrichment [w/o] }\end{array}$ \\
\hline 1 & 00000 & 1 & \multirow{19}{*}{ Fig. 3} & 1 & 4.65 \\
\hline 2 & 00001 & 2 & & 2 & 4.50 \\
\hline 3 & 00010 & 3 & & 3 & 4.40 \\
\hline 4 & 00011 & 4 & & 4 & 4.30 \\
\hline 5 & 00100 & 5 & & 5 & 4.20 \\
\hline 6 & 00101 & 6 & & 6 & 4.10 \\
\hline 7 & 00110 & 7 & & 7 & 4.00 \\
\hline 8 & 00111 & 8 & & 8 & 3.90 \\
\hline 9 & 01000 & 9 & & & \\
\hline 10 & 01001 & 10 & & & \\
\hline 11 & 01010 & 11 & & & \\
\hline 12 & 01011 & 12 & & & \\
\hline 13 & 01100 & 13 & & & \\
\hline 14 & 01101 & 14 & & & \\
\hline 15 & 01110 & 15 & & & \\
\hline 16 & 01111 & 16 & & & \\
\hline 17 & 10000 & 17 & & & \\
\hline 18 & 10001 & 18 & & & \\
\hline 19 & 10010 & 19 & & & \\
\hline 20 & 10011 & \multirow{2}{*}{\multicolumn{4}{|c|}{ *3-bit numbers only were used for the enrichment optimization }} \\
\hline$\ldots$ & $\ldots$ & & & & \\
\hline
\end{tabular}

Fig. 5. Encoding and Decoding Process for $\mathrm{UO}_{2} / \mathrm{Gd}_{2} \mathrm{O}_{3}$ Positions and Enrichments

\begin{tabular}{c|c|c|c}
\hline Parameter & 1 & 2 & 3 \\
\hline Genotype & 000 & 100 & 101 \\
\hline Phenotype & 1 & 5 & 6 \\
\hline $\begin{array}{c}\text { Corresponding } \\
\text { Enrichment }\end{array}$ & 4.65 & 4.20 & 4.10 \\
\hline $\begin{array}{c}\text { Position } \\
\text { (Fig. 4) }\end{array}$ & $\begin{array}{c}\text { CG } \\
\{1,2\}\end{array}$ & $\begin{array}{c}\text { GT } \\
\{3,4,5,6\}\end{array}$ & $\begin{array}{c}\text { IT } \\
\{7\}\end{array}$ \\
\hline
\end{tabular}

Fig. 6. Sample Phenotype and Genotype Structures for Enrichment Zoning

different kinds of enrichment can be obtained, but it is impractical to use several enrichments in an assembly, even though this solution can yield the best results in terms of both peak power and cycle energy.

To simplify the problem, the seven parameters were put into three groups, representing the fuel rods at positions $\{1,2\}$ adjacent to the $C G$, the fuel rods at position $\{3,4,5,6\}$ adjacent to the GT, and the fuel rod at $\{7\}$ adjacent to the IT, respectively, as shown in Fig. 4. The eight decision variables were then defined to represent their corresponding enrichments as shown in Fig. 5, which is a little different from the case above in which the decision variables represent positions. The types of enrichment considered here were $4.65,4.5,4.4,4.3,4.2,4.1,4.0$, and 3.9 w/o. With only eight different enrichments, the structure of the genotype was relatively simple because 3 bits per parameter can be used to express the corresponding phenotypes. Therefore, each population consists of 9 bits ( 3 bits per parameter). Figure 6 shows the sample structure of the phenotype and genotype for the enrichment zoning.

\subsection{Implementation}

The GA driver and the core design code package ALPHA/PHOENIX-P/ANC were integrated by the automated link code to perform the optimization calculations according to the sequence shown in Fig. 7. The code developed in this study was mainly used to manipulate the results from the GA code and to generate input data for the core design codes. After calculating the 3D core depletion, the code transferred the necessary information to the GA code to evaluate the fitness and to generate the next generation. The calculation repeats automatically until a given end condition is met. The 


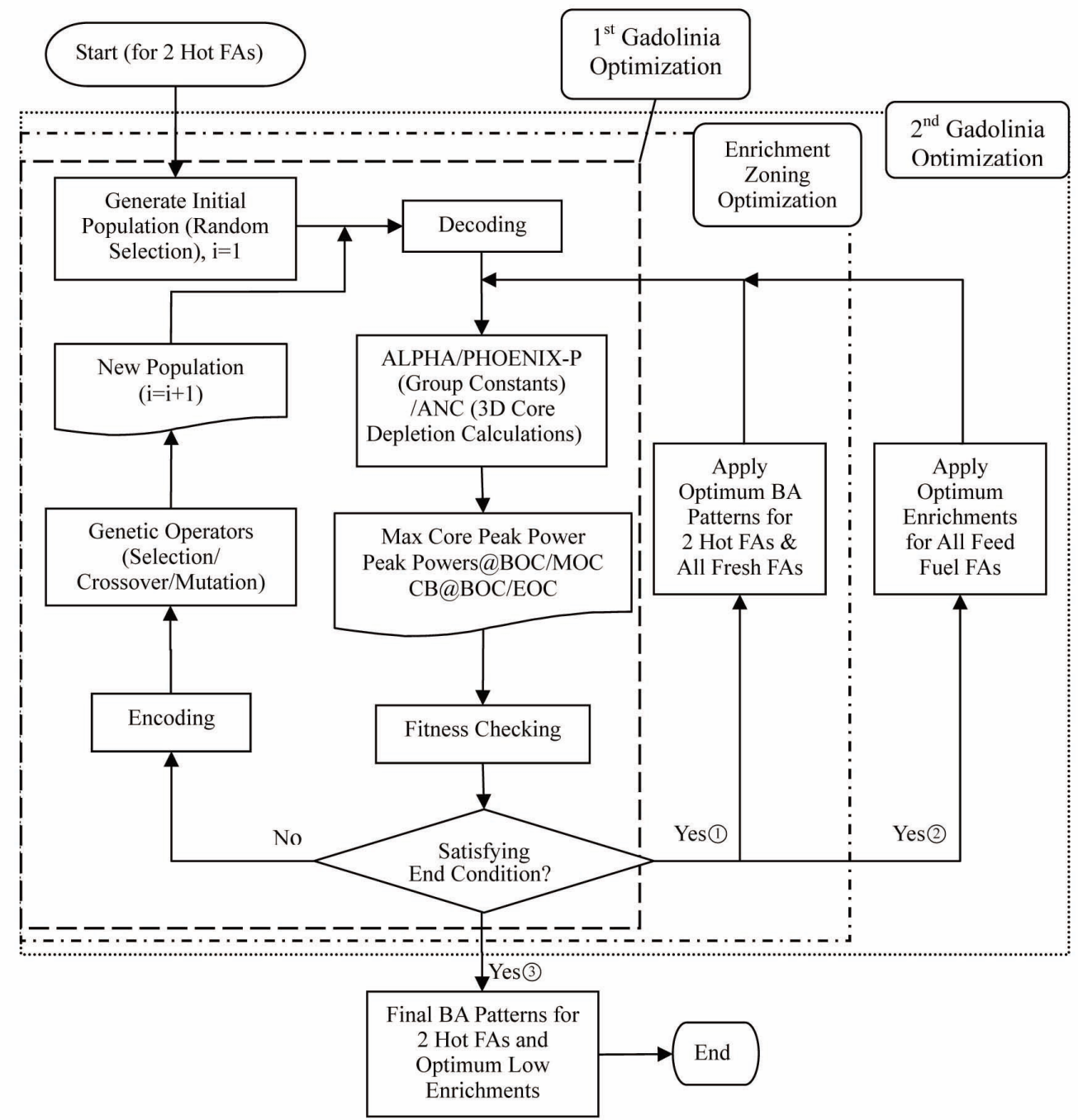

Fig. 7. GA algorithm Integrated with Core Depletion Codes

convergence criterion of the GA code was established by assigning a maximum generation number to ensure the fitness value had reached a maximum. As shown in Fig. 7, the optimizations were performed in the following steps:

1)Optimize gadolinia fuel rod positions simultaneously for two hot assemblies over the cycle.

2) Search for the optimum enrichments for each lowenriched zone of the hot assemblies after applying the results from step1) to the hot assemblies (Yes (1)).

3)Repeat step2) after applying the optimum enrichments obtained from step2) to all fresh fuels (Yes (1)).

4)Repeat step1) for two hot assemblies after assigning the optimum enrichments to each low-enriched zone for all fresh fuels in the core (Yes(2)).

As described in chapter 1, there are generally a few hot assemblies during the cycle. In the case of Ulchin Unit Cycle 11, the hot assemblies were respectively located at
$(2,4)$ and $(3,5)$ in the octant core symmetry. The gadolinia BA optimization was performed simultaneously only for these two hot assemblies. The advantages of the technique can be summarized as follows:

1)The simultaneous optimization technique for a few fuel assemblies provides more solutions than the independent optimization method. This problem included a total of 2,760,681 possible selections $\left({ }_{19 \times 2} \mathrm{C}_{3 \times 2}\right)$ when optimized simultaneously, but only 1,938 combinations $\left({ }_{19} \mathrm{C}_{3}\right.$ for each assembly $\left.\mathrm{x} 2\right)$ when optimized independently.

2) The computational time can be reduced by around $30 \%$ per series of calculations (GA-ALPHA/PHOENIX$\mathrm{P} / \mathrm{ANC}$ ) for each generation.

3) The simultaneous technique works as if treating all fresh fuels in the core simultaneously, while the independent approach focuses on each assembly individually. 
Table 1. Comparison of Results between Optimization Techniques

\begin{tabular}{c|c|c|c|c}
\hline \multirow{2}{*}{ Core Parameter } & \multicolumn{2}{|c|}{ Independent Optimization } & \multicolumn{2}{c}{ Simultaneous Optimization } \\
\cline { 2 - 5 } & FA at $(2,4)$ & FA at $(3,5)$ & FA at $(2,4)$ & FA at $(3,5)$ \\
\hline Number of $\mathrm{UO}_{2} / \mathrm{Gd}_{2} \mathrm{O}_{3}$ Rods & 20 & 12 & \multicolumn{2}{|c}{$2,7,17$} \\
\hline $\begin{array}{c}\mathrm{UO}_{2} / \mathrm{Gd}_{2} \mathrm{O}_{3} \text { Rod Positions } \\
\text { (in Octant FA Model) }\end{array}$ & $\{2,5,12\}$ & $\{5,19\}$ & 1.459 & 1.468 \\
\hline Maximum Peak Rod Power & 1.449 & 1.482 & \multicolumn{2}{|c}{} \\
\hline
\end{tabular}

*The reference positions are $\{4,14,19\}$ at $(2,4)$ and $\{4,17\}$ at $(3,5)$; see Fig. 3 to find their positions in the FA.

\subsection{Design Constraints and Objective Functions}

The following constraints were taken into account in these optimization processes:

1) The concentration of $\mathrm{Gd}_{2} \mathrm{O}_{3}$ must be less than or equal to $8 \mathrm{w} / \mathrm{o}$.

2) The critical boron concentration at EOC must be greater than the current value of Cycle 11.

3)Asymmetric BA patterns were not allowed.

4) The uranium enrichments of fuel rods in the highenriched zone and in $\mathrm{UO}_{2} / \mathrm{Gd}_{2} \mathrm{O}_{3}$ were fixed.

5) The uranium enrichment of fuel rods in low-enriched zones should not exceed that of the high-enriched zone.

6) The peak power should be less than the current maximum value.

7) The mixed concentration of $\mathrm{Gd}_{2} \mathrm{O}_{3}$ in an assembly was not allowed for practical use.

Violation of some constraints does not mean that the solution is infeasible, but exclusion of the solutions violating such constraints can narrow the searching space and trap the solutions in local optima that would be suitable for practical core designs. The objectives are to minimize the peak power over the cycle and to maximize the cycle lifetime (the critical boron concentration (CB) at EOC). The fitness function to be evaluated was defined as below:

$$
\begin{aligned}
& \text { Fitness }=\mathrm{f} 1+\mathrm{f} 2+\mathrm{f} 3, \\
& \begin{aligned}
\text { where } \mathrm{f} 1 & =\mathrm{w} 1 \times \mathrm{CB} \text { at EOC } \\
\mathrm{f} 2 & =\mathrm{w} 2 \times\left(\mathrm{C}_{\max }-\text { Maximum Peak Power }\right) \\
\mathrm{f} 3 & =\mathrm{w} 3 .
\end{aligned}
\end{aligned}
$$

Since the fitness function must be a nonnegative figure of merit [9], the coefficient $\mathrm{C}_{\max }$ was introduced to minimize the objective function (maximum peak power). The weight coefficients $\mathrm{w} 1=10$, w2 $=1000$, and $\mathrm{w} 3=10000$ were determined heuristically. The relative values, rather than the absolute values, of each weight coefficients are meaningful. The high negative penalty value of $-10,000$ for $\mathrm{w} 3$ was assigned to populations that violated the constraints described above in order to exclude the solutions and prevent them from being selected for the next generation. When the weight coefficient w1 was higher than the value above, the GA tended to converge to the populations with higher $\mathrm{CB}$ at EOC, while the peak powers did not decrease. In contrast, when w1 was too low or was not defined in an extreme case in the fitness function, the better BA patterns and/or an enrichment combination could be obtained in terms of peak power only, but in some cases it resulted in a decrease in cycle lifetime ( $\mathrm{CB}$ at EOC) compared with the reference loading pattern. These weight coefficients worked well in this study.

\section{RESULTS}

\subsection{Optimum Gadolinia Fuel Designs}

Table 1 shows a comparison of the optimized results between two different approaches for the same hot assemblies. First, in the independent optimization approach, the resulting numbers of optimized gadolinia BA remained as they were with 12 rods at $(3,5)$ and 20 rods at $(2,4)$, but the positions were optimized such that they gave peak power lower than those of the reference case (See Table 2 for the reference case). The second approach (in which two hot assemblies were optimized simultaneously) resulted in 16 rods at both locations, which differed from the original number of gadolinia fuel rods and provided a better solution than the independent approach. The maximum peak power at $(3,5)$ was decreased by up to $2.5 \%$ by the simultaneous optimization technique, while the independent optimization technique showed a decrease of $1.6 \%$ for the same fuel assembly. The results indicate that the simultaneous technique provides a better (or at least equal) solution compared with the independent optimization technique if the total number of BAs is assumed to be unchanged to meet the MTC limit or to prevent reduction in the cycle lifetime.

In earlier generations, the results from the simultaneous technique showed that the two hot assemblies evolved to their optimum solutions while keeping their original 
Table 2. Comparison of Reference and Optimal Designs

\begin{tabular}{|c|c|c|c|c|}
\hline \multirow[b]{2}{*}{ Core Parameter } & \multirow[b]{2}{*}{$\begin{array}{l}\text { Reference Core } \\
\text { (Current Design) }\end{array}$} & \multicolumn{3}{|c|}{ Simultaneous Optimization } \\
\hline & & $\mathrm{UO}_{2} / \mathrm{Gd}_{2} \mathrm{O}_{3}$ Designs & $\begin{array}{c}\mathrm{UO}_{2} / \mathrm{Gd}_{2} \mathrm{O}_{3} \text { and } \\
\text { Enrichments for only } 2 \\
\text { Hot FAs }\end{array}$ & $\begin{array}{c}\mathrm{UO}_{2} / \mathrm{Gd}_{2} \mathrm{O}_{3} \text { and } \\
\text { Enrichments for All } \\
\text { Fresh FAs }\end{array}$ \\
\hline $\begin{array}{l}\text { Number of } \mathrm{UO}_{2} / \mathrm{Gd}_{2} \mathrm{O}_{3} \\
\text { Rods in Hot FAs }\end{array}$ & $\begin{array}{l}20 \text { at }(2,4) \text {, } \\
12 \text { at }(3,5)\end{array}$ & \multicolumn{3}{|c|}{16 at $(2,4)$ and at $(3,5)$} \\
\hline $\begin{array}{c}\mathrm{UO}_{2} / \mathrm{Gd}_{2} \mathrm{O}_{3} \text { Rod Positions in } \\
\text { FA (Fig. 3) }\end{array}$ & $\begin{array}{c}\{4,14,19\} \text { at }(2,4) \\
\{4,17\} \text { at }(3,5)\end{array}$ & \multicolumn{3}{|c|}{$2,7,17$} at $(2,4)$ and $(3,5)$ \\
\hline $\begin{array}{c}\text { Enrichment }[\mathrm{w} / \mathrm{o}] \text { at Each Zone } \\
(\mathrm{CG} / \mathrm{GT} / \mathrm{IT})\end{array}$ & $4.1,4.1,4.1$ & $4.1,4.1,4.1$ & \multicolumn{2}{|c|}{$4.65 / 4.2 / 4.2$} \\
\hline $\begin{array}{l}\text { Maximum Peak Power } \\
\text { in Each FA, }(2,4) \&(3,5)\end{array}$ & $1.483,1.506$ & $1.459,1.468$ & $1.466,1.475$ & $1.463,1.471^{*}$ \\
\hline Maximum Peak Power in Core & 1.506 & 1.472 & 1.475 & 1.471 \\
\hline Critical Boron at EOC (ppm) & 10 & 10 & 13 & 23 \\
\hline $\begin{array}{l}\text { Cycle Length [EFPD] in Ideal } \\
\text { Equilibrium Cycle }\end{array}$ & 496 & & - & 501 \\
\hline
\end{tabular}

${ }^{*} 1.457,1.467$ when the enrichments are $4.65,4.1,4.1 \mathrm{w} / \mathrm{o}$.

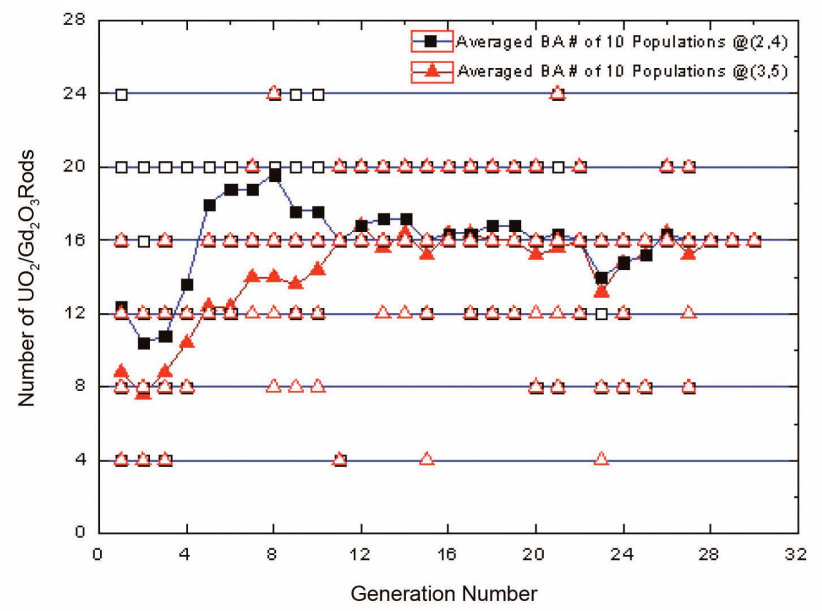

Fig. 8. Number of Gadolinia BA Rods as a Function of Generation

number of BAs, but as the generation repeated, the optimum number of BAs for the hot assemblies evolved to a third number that provided a better solution. Figure 8 shows the progress of the evolution to the number of BAs.

\subsection{Optimum Enrichments of Low Zones}

Before optimizing the BA designs, the first trial to optimize the enrichment of low enriched zones was unsuccessful. The resulting enrichments were 4.3, 4.2, and $3.7 \mathrm{w} / \mathrm{o}$ in the CG, GT, and IT zones, respectively, and the resulting maximum peak power decreased by only 0.001 . This unsuccessful result was due to the fact that the slight variations in enrichment of the zones of the lower enrichment fuel pins do not impact the peak power as much as the variations in BA pattern do. Thus, this approach was terminated, and the order was switched to optimize the BA patterns first. After applying the optimized BA designs from the first step described in Section 3.3, the optimum enrichments of three low zones were effectively obtained.

Table 2 compares the reference core designs and three optimal designs obtained by applying the algorithm shown in Fig. 7. The final enrichments of $4.65,4.2$, and $4.2 \mathrm{w} / \mathrm{o}$ in $\mathrm{CG}, \mathrm{GT}$, and IT, respectively, were obtained after applying the initially optimized ones (step 2) to all fresh fuels. Coupled with the optimum BA designs, the optimum lower enrichments increased the average enrichment by around $0.045 \mathrm{w} / \mathrm{o}$ in the non-gadolinia-bearing assembly basis. This difference in enrichment increased the cycle lifetime around 5 EFPD on an ideal equilibrium cycle basis as shown in Table 2, which resulted in an additional electricity sales profit of $\$ 5.14$ million after offset fuel costs per cycle and plant.

The final gadolinia fuel rod designs optimized after applying the optimum enrichments were found to be the same as those of the initial results. The 20 and 12 gadolinia fuel rods at $(2,4)$ and $(3,5)$, respectively, were finally optimized to 16 rods at both locations. The determined positions of the gadolinia fuel rods were at $\{2,7,17\}$ in the octant assembly model shown in Fig. 3. The resulting maximum peak power was 1.463 and 1.471 in each fuel 


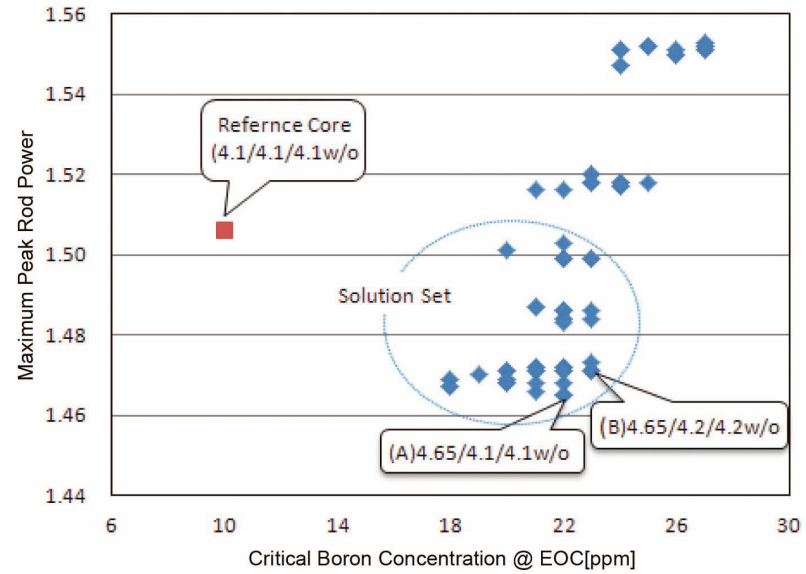

Fig. 9. Maximum Peak Rod Power versus CB at EOC

assembly, which were slightly higher than those (1.457 and 1.467) from the low zone enrichments of 4.65, 4.1, and $4.1 \mathrm{w} / \mathrm{o}$ when the same optimized gadolinia BA designs were applied. This means that the optimized enrichments $(4.65,4.2$, and $4.2 \mathrm{w} / \mathrm{o})$ were not the best solution with regard to peak power, as shown in Fig. 9.

As indicated in Fig. 9, there is an acceptable solution set for which the peak rod power and the cycle lifetime are better than those of the reference case. The best solution in terms of the peak rod power is point (A), which resulted from the enrichments of $4.65,4.1$, and $4.1 \mathrm{w} / \mathrm{o}$ at CG, GT, and IT zones, respectively. However, there is a solution for which the critical EOC boron concentration is the maximum among the solutions, and its peak rod power is still much smaller than that of the reference case. In that sense, solution (B) can be chosen as a candidate solution from two objective points of view (minimizing the peak power and maximizing the cycle lifetime). Even though the peak power of 1.471 at $(\mathrm{B})$ is $0.27 \%$ higher than the value of 1.467 at (A), solution (B) can be regarded as the optimum solution of this study because its cycle lifetime is the best, and an economic effect should be given more weight unless its maximum peak power has an adverse effect on operational margins.

If the weight coefficient w1 in equation (1) is given more weight, the solutions tend to move to the upper right region in Fig. 9. In contrast, when w2 was given more weight, the solutions moved in the opposite direction. The weight coefficients were determined heuristically as described in Section 3.4.

\section{CONCLUSIONS}

The GA driver and the core design code package ALPHA/PHOENIX-P/ANC were integrated by the automated link code developed in this study, and this code package was used to optimize the gadolinia fuel rod patterns and the enrichments of low enriched zones. It was found that the simultaneous optimization technique introduced in this study was more effective and efficient than the other technique as described in Section 4.1. Coupled with the optimum gadolinia fuel rod designs, the lower enrichments in the PLUS7 assembly were also optimized to $4.65,4.2$, and $4.2 \mathrm{w} / \mathrm{o}$ in the $\mathrm{CG}$, GT, and IT zones, respectively, instead of the current values of 4.1, 4.1, and $4.1 \mathrm{w} / \mathrm{o}$. The enrichment set also can be applied to the fresh fuels in any cycles, or to the other similar PWR cores that use the same PLUS7 fuel, unless the higher enrichment in the assembly is changed because the enrichments are not sensitive to loading patterns in terms of peak power. The optimum enrichment coupled with the optimum gadolinia fuel rod designs resulted in an additional electricity sales profit of $\$ 5.14$ million after accounting for offset fuel costs per cycle and plant on an ideal equilibrium cycle basis.

Conversely, since the optimum gadolinia patterns depend on the characteristics of the surrounding fuels, i.e., the loading pattern of interest, the optimized gadolinia fuel rod designs based on certain loading patterns might not be applicable to the other loading patterns. Therefore, optimizing gadolinia fuel rod designs in advance for wide use is not recommended. Instead, we recommend the simultaneous optimization technique for a few hot assemblies during the cycle in order to identify the cyclespecific optimum BA designs as done in this study. In the next cycle, the BA designs optimized in the previous cycles can be first applied to optimize a loading pattern, and then applying the same technique developed in this study to a few hot assemblies can be expected to obtain a good solution.

When the simultaneous optimization technique was applied to two hot assemblies, around 14 CPU minutes were required to process one generation by the integrated code package GA-APLHA/PHOENIX-P/ANC. Finally, it took 8.2 CPU hours to obtain the optimum gadolinia fuel rod designs. Therefore, it is expected that in reactor cores loaded with PLUS7 fuels, the technique developed in this study can be effectively used to obtain a satisfactory solution quickly during the practical design of loading patterns.

\section{REFERENCES}

[1] PLUS7 Fuel Design and Safety Evaluation for Korean Standard Nuclear Power Plants, KNF-TR-DMR-04001, March 2006.

[2] The Nuclear Design Report for Yonggwang Unit 3 Cycle 1, 9-421-0-700-004, December 1994.

[3 ] S. W. PARK, et. al., The Evaluation for Optimized PWR Cycle Length Operation, H07S007000, May 2008.

[4 ] D. CARROL, "FORTRAN Source of Genetic Algorithm Code," available on the Internet at www.cuaerospace.com/ ga.html. 
[5] T. Q. Nguyen, et. al., Qualification of the PHOENIX$\mathrm{P} / \mathrm{ANC}$ Nuclear Design System for Pressurized Water Reactor Cores, WCAP-11596-P-A, June 1988.

[6] Y. S. Liu, et. al., ANC: A Westinghouse Advanced Nodal computer Code, WCAP-10965-P-A, September 1986.

[7] S. YILMAZ, K. IVANOV, and S. LEVINE, "Genetic Algorithm to Optimize the $\mathrm{UO}_{2} / \mathrm{Gd}_{2} \mathrm{O}_{3}$ Fuel Pin Designs in a Pressurized Water Reactor," Nucl. Technol., 156, 168 (2006).
[8] S. YILMAZ, K. IVANOV, S. LEVINE and M. MAHGEREFTEH, "Genetic Algorithm Application for Burnable Poison Placement in PWRs with Optimized $\mathrm{UO}_{2} / \mathrm{Gd}_{2} \mathrm{O}_{3}$ Fuel Pin Configurations," Nucl. Technol., 156, 180 (2006).

[9] D. E. GOLDBERG, Genetic Algorithms in Search, Optimization, and Machine Learning, Addison-Wesley, 1989

[10] H. KITANO, Genetic Algorithm, Daechung Information System, 1996(Korean Translated Version) 